\title{
Características do sistema produtivo da pecuária no município de Santarém, Pará
}

\author{
Antonio Humberto Hamad MINERVINO ${ }^{1}$, Elyzabeth da Cruz CARDOSO², Enrico Lippi ORTOLANI ${ }^{1}$ \\ RESUMO \\ Com o objetivo de identificar as principais falhas no sistema de produção que limitam a pecuária em Santarém, Pará, foram \\ entrevistados, ao acaso, 21 pecuaristas ( $90,5 \%$ de corte - cria, recria e engorda; $9,5 \%$ de leite), proprietários de $10 \%$ da população \\ de bovinos do município. $71,4 \%$ das propriedades tinham currais para manejo do gado, entretanto apenas 38,1\% possuíam \\ balança e 23,8\% tronco de contenção. A Brachiaria brizantha estava presente em todas as fazendas, sendo usada exclusivamente \\ em $42,9 \%$ das propriedades. A disseminação de plantas invasoras $(61,9 \%)$ foi considerada a principal dificuldade no manejo \\ das pastagens. Constatou-se que $76,2 \%$ dos pecuaristas utilizam misturas minerais com macro e micro-elementos, geralmente \\ de formulações comerciais, enquanto que $19 \%$ utilizam apenas sal comum, enriquecido com micro-elementos. A concentração \\ de fósforo $(\mathrm{P})$ na mistura mineral estava abaixo do recomendado para bovinos de corte em $76,9 \%$ das propriedades e apenas \\ $19 \%$ das propriedades possuía cochos para suplementação mineral adequada.
}

PALAVRAS-CHAVE: Bovinos, Minerais, Suplementação, Fósforo, Manejo de pastagens.

\section{Characterization of cattle production systems in Santarém, Pará, Brazil}

\section{ABSTRACT}

With the objective of identifying the main problems of cattle nutrition in the production systems of Santarém, Pará, Brazil, ranchers in different regions of the municipality and who owned $10 \%$ of the municipality's animals were interviewed at random. The ranchers raised mostly beef cattle; only $9.5 \%$ had dairy cattle. The infrastructure conditions are inappropriate; only $23.8 \%$ of the ranches have adequate facilities for beef cattle management and $61.9 \%$ of the ranchers do not consider weight control. Weed invasion was considered the main problem of the pastures (61.9\%). The most common forage was Brachiaria brizantha, used exclusively in $42.9 \%$ of the ranches. $76.2 \%$ of the ranchers used a complete mineral supplement, with macro and micro elements, while $19 \%$ used only salt $(\mathrm{NaCl})$ with micro elements; the other $5 \%$ did not use mineral supplements at all. The phosphorus concentration in the mineral supplement at $76.9 \%$ of the ranches was less than the minimum level suggested for beef cattle and only $19 \%$ of the ranches had appropriate mineral feeders.

KEYWORDS: Bovine, Mineral supplements, Phosphorous, Pasture management.

\footnotetext{
1 Departamento de Clínica Médica. Faculdade de Medicina Veterinária e Zootecnia - FMVZ - USP - Av. Prof. Orlando Marques de Paiva, 87, CEP 05508-900, São Paulo/SP. e-mail: hhamad@usp.br

2 Departamento de Clínica e Patologia. Universidade Federal Fluminense - UFF
} 


\section{INTRODUÇÃO}

Na Amazônia, o Pará é o estado em que a pecuária é mais importante, com o quinto rebanho bovino brasileiro de mais de 17 milhōes de cabeças, e extraordinário crescimento anual de cerca de $16 \%$. A pecuária é a principal atividade econômica em $51 \%$ dos municípios paraenses. $\mathrm{O}$ abate anual é em torno de 1,1 milhôes de cabeças, além da comercialização de $800 \mathrm{mil}$ animais vivos (IBGE, 2004; ANUALPEC, 2004).

$\mathrm{O}$ estado tem grande potencial para o incremento dessa atividade, devido à vasta extensão territorial e condiçōes climáticas apropriadas, como alta insolação, ausência de estação fria, elevadas temperatura e pluviosidade, propícias para o desenvolvimento das gramíneas tropicais. A mesorregião do Baixo Amazonas é, sem dúvida, uma das mais problemáticas do estado, com rebanhos que ainda enfrentam restriçôes devido à febre aftosa. Santarém é a maior cidade dessa mesorregião e possui uma problemática superior, observada pelo menor número de animais e inferior produtividade em relação aos municípios vizinhos, de menor desenvolvimento sócio-econômico (Minervino et al., 2004).

O levantamento do manejo utilizado em rebanhos pecuários é de grande valia para detectar pontos de estrangulamento da cadeia produtiva passíveis de modificaçôes. A identificação das características gerais das propriedades, do manejo do solo e das pastagens, e da suplementação mineral constituem fatores determinantes para estabelecer índices produtivos, caracterizar fatores responsáveis pela menor produtividade e estabelecer medidas a serem recomendadas e adotadas pelos produtores visando aumento da produtividade com maior sustentabilidade. Dessa maneira, este trabalho propôs estabelecer alguns índices produtivos da pecuária no município de Santarém, Pará, visando definir os principais problemas que afetam a sua produtividade.

\section{MATERIAL E MÉTODOS}

O trabalho foi realizado no município de Santarém, mesorregião do Baixo Amazonas, estado do Pará, no período de maio a setembro de 2003. Os dados foram obtidos por meio de entrevistas com proprietários rurais, os quais foram selecionados de forma inteiramente ao acaso, utilizando-se como base a relação de sócios do Sindicato dos Produtores Rurais de Santarém. A amostragem incluiu 21 pecuaristas, responsáveis pela criação de $10 \%$ do rebanho do município, cerca de 10.000 bovinos, e aproximadamente $2,5 \%$ do total de propriedades cadastradas, de acordo com dados de 2002 da Secretaria Executiva de Agricultura do estado do Pará (SAGRI, 2002). Foi realizada a análise estatística descritiva dos resultados para determinação de médias e frequiências de cada alternativa, e para os cálculos de consumo de sal mineral e de composição mineral das misturas utilizadas.
Inicialmente, foi realizada a identificação das propriedades, estabelecendo-se uma visão geral do sistema produtivo pecuário, visando definir o tipo de atividade, animais utilizados e nível de exploração. Foram coletadas informaçôes sobre manejo do solo e das pastagens, e quais as práticas de conservação utilizadas.

Posteriormente, foram coletados dados sobre as características da suplementação mineral dos rebanhos, avaliando as concentraçôes dos macro e micro-elementos das misturas minerais e o manejo do seu fornecimento, bem como o conhecimento dos produtores sobre a sua importância no desempenho animal. O consumo de sal mineral foi calculado de acordo com a quantidade total de suplemento utilizado na propriedade, dividido pelo número de animais. As concentraçôes de fósforo $(\mathrm{P})$ das misturas de minerais foram estabelecidas através dos rótulos dos produtos comerciais ou por meio de cálculos nos suplementos de formulação caseira.

\section{RESULTADOS E DISCUSSÃO}

\section{CARACTERISTICAS GERAIS E MANEJO DOS SOLOS E PASTAGENS}

Verificou-se que $47,6 \%$ das propriedades apresentavam de 20 a $50 \%$ da área total transformada em pastagens, enquanto que $19 \%$ possuíam alta exploração da área $(50$ a $85 \%$ da área total convertida em pastagem) e $23,8 \%$ das propriedades apresentavam intensiva exploração (mais de $85 \%$ de área de pastagem). Apenas 9,5\% das propriedades visitadas se encontravam de acordo com as normas do IBAMA para a região, que é de no máximo $20 \%$ de sua área total convertida em pastos. Ainda assim, esses resultados se destacam, do ponto de vista ambiental, quando comparados aos de Veiga \& Tourrand (2000) com produtores de leite na zona Bragantina, Pará, onde a média da área de pasto era de $74 \%$ do total da propriedade, ou alta exploração.

A atividade pecuária do município de Santarém caracterizase pela produção de carne, com propriedades voltadas para a produção de bezerros para engorda, com reduzido numero de propriedades em atividade leiteira (9,5\%). A espécie utilizada, em larga escala, era a bovina (90,5\%), enquanto que em apenas $9,5 \%$ das propriedades eram observados búfalos e bovinos. Em nenhuma das propriedades visitadas foi observada a criação exclusiva de búfalos. A raça Nelore foi criada de maneira exclusiva em $47,6 \%$ das propriedades, e associada com outras raças em $28,6 \%$. Em 14,3\% das propriedades os bovinos não apresentavam padrão definido, com alto grau de segregação racial e 9,5\% das fazendas utilizavam raças com aptidão leiteira.

Com relação à infra-estrutura, $71,4 \%$ das propriedades possuíam curral com brete e $23,8 \%$ possuíam tronco de contenção, semelhante aos observados por Vieira et al. (2002), 
no município de Uruará, Pará, onde 60\% das propriedades possuíam curral e 16\% tronco. Foi constatado em Santarém que em $61,9 \%$ das propriedades os currais não tinham balança, item importante para avaliar a eficiência de produção de carne, e nas propriedades que possuíam balança não existia rotina de pesagem para o acompanhamento do desempenho ponderal.

Pouco mais da metade dos produtores $(52,4 \%)$ já realizaram análise do solo, primeira etapa do processo de manejo e conservação do solo, e que permite o conhecimento dos teores minerais do solo, possibilitando a interpretação do estado de degradação e da sua qualidade. Cerca de $28 \%$ dos produtores já realizou aplicação de calcário, contudo, na maioria dos casos, em quantidades inferiores as recomendada pela análise do solo. Foi constatado que a calagem foi realizada em área que nunca superior a 50\% da pastagem cultivada e na maioria dos casos limitou-se a um número reduzido de hectares. $\mathrm{O}$ uso de calagem no estabelecimento ou recuperação de pastagem na Amazônica não parece se justificar, uma vez que as espécies forrageiras utilizadas toleram bem os solos ácidos (Veiga \& Falesi, 1986). As vantagens dessa prática, no entanto, estão relacionadas à elevação dos teores de cálcio e magnésio no solo e a maior disponibilidade do $\mathrm{P}$, ao invés do efeito corretivo da acidez (Mattos et al., 1986).

As deficiências nutricionais encontradas em solos de pastagens variam de acordo com o tipo de solo, adubação usada no plantio e manejo do sistema solo-planta-animal. Entretanto, nas condições de solos ácidos e de baixa fertilidade predominantes nas áreas tropicais e subtropicais do Brasil, deficiências de nitrogênio e fósforo são comuns na maioria das situaçôes (Carvalho, 1993). A parcela de produtores que efetuou adubação química do solo foi de $19 \%$ sugerindo falta de conhecimento ou consciência sobre o assunto, ou falta de meios.

Em 75\% das propriedades as pastagens foram formadas há mais de cinco anos. Os $25 \%$ restantes tinham pastos formados entre dois e cinco anos. Dentre as gramíneas forrageiras utilizadas destacou-se a Brachiaria brizantha, cv Marandú (Braquiarão), presente em todas as fazendas; em $42,9 \%$ destas, essa gramínea era cultivada exclusivamente. Pastagens formadas por Brachiaria humidicola (quicuio-da-amazônia) e Panicum maximum cv. Mombaça foram observadas em $38,9 \%$ e $23,8 \%$ das propriedades, respectivamente. O plantio consorciado entre a Brachiaria brizantha e espécies de panicum $s p$. foi relatada como prática comum, entretanto, após alguns anos a primeira espécie se sobrepõe eliminando a segunda. $\mathrm{O}$ uso de leguminosas cultivadas na região ainda é pouco difundido, sendo observado apenas o aproveitamento das espécies nativas. $\mathrm{O}$ uso de espécies de gramíneas cultivadas separadamente, com manejo adequado as suas características individuais, bem como o uso de leguminosas com alto teor de proteína bruta e capacidade de repor nitrogênio ao solo são práticas recomendada para a região Amazônica e não utilizadas no município de Santarém (Costa et al., 2000).

Em $71,4 \%$ das propriedades o manejo das pastagens apresentava sistema de rodízio, caracterizado por um número reduzido de piquetes, com longo período de ocupação, enquanto que $28,8 \%$ utilizavam o sistema de pastejo continuo. Esses resultados são semelhantes aos encontrados por Veiga \& Tourrand (2000), na zona Bragantina, nordeste paraense. Pesquisas têm comprovado que o sistema de pastejo rotacionado intensivo com rigoroso controle da disponibilidade de forragem, quando cada piquete é pastejado por apenas 30 dias/ano, permite obter desempenho produtivo superior em oito vezes aos encontrados na Amazônia (Costa et al., 2000).

A disseminação de plantas invasoras nas pastagens foi considerada como o principal problema no manejo $(61,9 \%$ das propriedades), provavelmente pela baixa fertilidade do solo, em função do elevado tempo de sua implantação, o que provoca o início da sua degradação. A estiagem, que também pode ter influência no processo de degradação, foi relatada por $23,8 \%$ dos produtores, como a principal adversidade no manejo das pastagens. Na maioria das fazendas $(80,9 \%)$ não se utiliza a queima periódica dos pastos, prática que traz resultados satisfatórios, em curto prazo, no controle de plantas invasoras, mas contribui para a degradação dos solos (Mattos et al., 1986).

\section{CARACTERÍSTICAS DA SUPLEMENTAÇÃO MINERAL}

A quase totalidade dos produtores $(95,5 \%)$ acha que a suplementação mineral eleva a produtividade e mais da metade $(52,4 \%)$ deles não acredita que existe diferença na necessidade mineral dos animais nas diferentes épocas do ano. Os que têm noção desse fato, não sabiam afirmar em qual período do ano há maior demanda por minerais. Durante o período seco os animais têm menor necessidade de minerais, devido à redução dos níveis de proteína e energia nas forrageiras, o que se traduz em menor desempenho e, conseqüentemente, redução na demanda de minerais, o que varia de acordo com a produtividade animal (McDowell, 1999; Carvalho et al., 2003). A suplementação mineral dos rebanhos sob pastejo na região dos trópicos é amplamente utilizada, sendo que em algumas regiôes do Brasil já se percebe elevada eficiência em relação a essa prática de manejo. No entanto, pode-se observar, com freqüência, que a suplementação mineral é efetuada de maneira inadequada, desconsiderando a categoria $\mathrm{e}$ as reais necessidades do animal/espécie, a época do ano e a qualidade do alimento consumido (Veiga \& Láu, 1998). Como alternativa para adequar a suplementação durante o período seco, o oferecimento de suplementos protéicos e energéticos, por exemplo, sob a forma de uréia e concentrados, constituem alternativas para elevar a produtividade animal 


\begin{tabular}{lc}
\hline $\begin{array}{l}\text { Tabela 1 - Características da suplementação mineral dos bovinos criados no } \\
\text { município de Santarém - Pará. }\end{array}$ & Porcentagem (\%) \\
\hline Mineralização do rebanho & 0,0 \\
\hline Não realiza suplementação & 4,7 \\
Utiliza apenas sal grosso & 19,1 \\
\hline Sal grosso + microminerais & 76,2 \\
\hline Sal comum + Macro e microminerais & \\
Níveis de fósforo na mistura mineral & 30,8 \\
\hline Sem P & 46,1 \\
Menor que 8\% de P & 15,4 \\
\hline Entre 8 e 10\% de P & 7,7 \\
\hline Maior que 10\% de P & \\
\hline
\end{tabular}

na região amazônica (Carvalho et al., 2003). As misturas minerais, que contêm esses ingredientes, são as denominadas "misturas múltiplas", existentes, em numerosas formulações, à disposição no mercado.

Foi observado que a grande maioria dos produtores $(85,7 \%)$ tem conhecimento que as deficiências minerais podem causar doenças e interferir na produtividade. Contudo, menos de um quarto deles $(23,8 \%)$ conhece a diferença de necessidade mineral, em função da categoria animal, e menos da metade $(42,9 \%)$ reconhece os sintomas clássicos de deficiências minerais específicas, como apetite depravado, anomalias ósseas, fraturas freqüentes, anomalias da pele e baixa fertilidade (Tokarnia et al., 2000).

Observa-se que a maioria dos produtores utiliza misturas minerais completas, com macro e micro-elementos, geralmente oriundos de formulaçóes comerciais (Tabela 1). Esse fato indica um razoável conhecimento prático sobre a suplementação mineral. São poucos os produtores $(23,8 \%)$ que ainda fazem uso de práticas inadequadas, como a utilização de apenas sal comum $(4,8 \%)$ ou sal enriquecido apenas com micro-elementos (19\%).

$\mathrm{O}$ grande problema observado foi em relação às concentrações de elementos minerais dos suplementos utilizados, que geralmente não atendem as exigências especifica da região, principalmente em relação ao fósforo. Uma mistura mineral deve conter no mínimo $6 \%$ de $\mathrm{P}$ em sua composição, enquanto concentrações de $8 \%$ de $\mathrm{P}$ são necessárias para atender as necessidades minerais de bovídeos em regiōes tropicais muito deficientes (Moraes, 2001).

Devido ao desconhecimento da importância do P, e para redução dos custos com sal mineral, mais de 76\% dos produtores não forneciam aos seus animais as quantidades suficientes desse elemento na mistura mineral, sendo que em $30,8 \%$ das propriedades o P não era utilizado. Tal deficiência
Tabela 2 - Características dos cochos, do fornecimento e do consumo da suplementação mineral no município de Santarém - Pará.

\begin{tabular}{lc}
\hline Cochos de mistura mineral & Porcentagem (\%) \\
\hline Improvisado & 28,6 \\
Coberto & 52,4 \\
\hline Coberto e com proteção lateral & 19,0 \\
\hline Fornecimento da mistura mineral & \\
\hline Ad libitum & 57,1 \\
\hline Restringido & 42,9 \\
\hline Intervalo de fornecimento & \\
Todo dia & 63,2 \\
\hline A cada dois días & 10,5 \\
\hline A cada três días & 21,0 \\
\hline Uma vez por semana & 5,3 \\
\hline Consumo estimado de mistura mineral & \\
\hline Menor que $30 \mathrm{~g} /$ dia & 19,0 \\
\hline Entre 30 e $70 \mathrm{~g} /$ dia & 28,6 \\
\hline Maior que $70 \mathrm{~g} /$ dia & 23,8 \\
\hline Não sabe & 28,6 \\
\hline
\end{tabular}

pode ser considerada como um dos principais problemas produtivos da pecuária no município de Santarém.

Uma constatação importante foi a de que mais de um quarto dos produtores $(28,6 \%)$ desconhecia a quantidade de sal mineral gasto na propriedade, o que demonstra a falta de profissionalismo, pois os custos com suplementação mineral têm grande importância na pecuária de corte $(\mathrm{McD}$ owell, 1999).

Além das características do sal mineral, o manejo de oferecimento das misturas é de extrema importância para a adequada suplementação do rebanho. Observou-se que o manejo de fornecimento de misturas minerais é adequado (Tabela 2), em parcela expressiva dos produtores, com mais de $57 \%$ de propriedades em que o animal tem livre acesso ao cocho, e $63,2 \%$ com abastecimento diário de mistura mineral, para evitar desperdícios. Devido à presença de chuvas torrenciais e sem direção determinada durante o período chuvoso, faz-se necessária a utilização de cochos cobertos e com proteção lateral no município de Santarém.

Foi verificado que o principal problema em relação ao manejo de fornecimento de suplementação mineral foi em relação aos cochos, os quais se encontravam inadequados para a região, em mais de $80 \%$ das propriedades.

\section{CONCLUSÕES}

O município de Santarém apresenta uma pecuária predominantemente de corte, voltada para produção de bezerros e engorda de garrotes. As pastagens utilizadas sofrem processo de degradação com grande presença de plantas invasoras. Um manejo do solo e de pastagens mais 
adequado, com adubação do solo e intensificação do pastejo rotacionado, bem como a utilização de gramíneas mais produtivas, poderiam ser alternativas para o incremento da produtividade animal. Foi observada falta de profissionalismo dos produtores, considerando-se que a maioria não possui infra-estrutura adequada para avaliar a produtividade, e não possuem informaçôes mínimas sobre o desempenho do seu rebanho. A suplementação mineral com macro e micro elementos é amplamente utilizada, no entanto, as baixas concentrações de $\mathrm{P}$ nas misturas minerais constituem fator limitante da produtividade. Como o município se caracteriza pela exploração da pecuária de corte, o desconhecimento do produtor sobre o real desempenho produtivo do rebanho dificulta a adoção de novas tecnologias, tais como recuperação de pastagens, suplementação alimentar e correta mineralização, pois sem o controle do ganho de peso não é possível avaliar o retorno econômico da produção de carne.

\section{BIBLIOGRAFIA CITADA}

ANUALPEC. 2004. Anuário da Pecuária Brasileira. FNP Consultoria e Agroinformativos, São Paulo, SP. 400pp.

Carvalho, M.M. 1993. Recuperação de pastagens degradadas. Série Documentos, 55, EMBRAPA Gado de Leite, Coronel Pacheco, MG. 51pp.

Carvalho, F.A.N.; Barbosa, F.A.; McDowell, L.R. 2003. Nutrição de bovinos a pasto. Editora PapelForm, Belo Horizonte, MG. 438pp.

Costa, N.A.; Moura Carvalho, L.O.D.; Teixeira, L.B.; Simão Neto, M. 2000. Manejo de pastagens na Amazônia. Embrapa Amazônia Oriental, Belém, PA. 151pp.

IBGE. 2004. Produção da Pecuária Municipal. Instituto Brasileiro de Geografia e Estatística, Rio de Janeiro. Disponível em www. ibge.gov.br. Acesso em 10/11/2004.
Mattos, H.B.; Werner, J.C.; Yamada, T.; Malavolta, E. 1986. Calagem e adubação de pastagens. Associação Brasileira para Pesquisa da Potassa e do Ferro, Piracicaba, SP. 476pp.

McDowell, L.R. 1999. Minerais para ruminantes sob pastejo em regiöes tropicais, enfatizando o Brasil. University of Florida, Gainesville, FL, USA. 92pp.

Minervino, A.H.H.; Cardoso, E.C.; Rodrigues, R.; Sá, C.F.B. 2004. Características gerais do sistema produtivo da pecuária no município de Santarém, Pará. In: IV Conferência Sul-Americana de Medicina Veterinária, Rio de Janeiro. Revista da Universidade Rural - Série Ciências da Vida, 24(supl.): 545-546.

Moraes, S.S. 2001. Importância da suplementação mineral para bovinos de corte. Série Documentos, 114, Embrapa Gado de Corte, Campo Grande, MS. 34pp.

SAGRI. 2002. Efetivo pecuário do Estado do Pará. Secretaria Executiva de Agricultura do Estado do Pará, Belém.

Tokarnia, C.H.; Dobereiner, J.; Peixoto, P.V. 2000. Deficiências minerais em animais de fazenda, principalmente bovinos em regime de campo. Pesquisa Veterinária Brasileira, 20(3): 127138.

Veiga, J.B.; Falesi, I.C. 1986. Recomendação e prática da adubação de pastagens na Amazônia brasileira. In: Mattos, H.B.; Werner, J.C.; Yamada, T.; Malavolta, E. (Eds). Calagem e adubação de pastagens. Associação Brasileira para Pesquisa da Potassa e do Ferro, Piracicaba, SP. p.256-282.

Veiga, J.B.; Láu, H.D. 1998. Manual sobre deficiência e suplementação mineral do gado bovino na Amazônia Oriental. Embrapa Amazônia Oriental, Belém, PA. 36pp.

Veiga, J.B.; Tourrand, J.F. 2000. Produção leiteira na Amazônia Oriental: situação atual e perspectivas. Embrapa Amazônia Oriental, Belém, PA. 234pp.

Vieira, L.C.; Veiga, J.B.; Freitas, C.M.K.H. 2002. Qualidade do leite nas propriedades do Município de Uruará, Pará. Comunicado Técnico, 69, Embrapa Amazônia Oriental, Belém, PA. 5pp.

Recebido em 20/06/2006

Aceito em 05/12/2007 
